\title{
KERGOMARD (Geneviève et Alain). - Pauline Kergomard
}

Rodez : Fil d'Ariane, 2000. - 360 p.

Eric Plaisance

\section{OpenEdition}

\section{Journals}

Édition électronique

URL : https://journals.openedition.org/histoire-education/882

DOI : 10.4000/histoire-education.882

ISSN : 2102-5452

Éditeur

ENS Éditions

Édition imprimée

Date de publication : 1 janvier 2001

Pagination : 182-183

ISBN : 2-7342-0868-7

ISSN : 0221-6280

\section{Référence électronique}

Eric Plaisance, «KERGOMARD (Geneviève et Alain). - Pauline Kergomard», Histoire de l'éducation [En

ligne], 89 | 2001, mis en ligne le 14 janvier 2009, consulté le 20 mai 2021. URL : http://

journals.openedition.org/histoire-education/882 ; DOI : https://doi.org/10.4000/histoire-education.882

Ce document a été généré automatiquement le 20 mai 2021.

(c) Tous droits réservés 


\section{KERGOMARD (Geneviève et Alain). - Pauline Kergomard}

Rodez : Fil d'Ariane, 2000. - 360 p.

Eric Plaisance

\section{RÉFÉRENCE}

KERGOMARD (Geneviève et Alain). - Pauline Kergomard. - Rodez : Fil d'Ariane, 2000. -

$360 \mathrm{p}$.

1 Pauline Kergomard est la figure centrale de l'évolution de la salle d'asile à l'école maternelle, au tournant des deux siècles précédents. Elle fut, en effet, d'abord «déléguée générale à l'inspection des salles d'asile " (en 1879, grâce à l'appui de Ferdinand Buisson), puis «inspectrice générale des écoles maternelles", à partir de 1881 et jusqu'à la période de la Première Guerre mondiale, en 1917. Si son nom figure aujourd'hui au fronton de quelques écoles maternelles, son œuvre et son importance restent encore relativement mal connues. Son livre essentiel L'Éducation maternelle dans l'école, qui est une reprise de ses nombreux articles de revue, n'a été que partiellement réédité en 1974 et des extraits figurent dans notre présentation de 1996'. Le présent ouvrage s'intitule simplement Pauline Kergomard et se trouve signé par deux de ses arrière-petits enfants. Il s'agit, pour l'essentiel (plus de la moitié des pages), de la correspondance envoyée par Pauline Kergomard à ses propres fils. Ce corpus est malheureusement partiel, car un certain nombre de lettres ont été détruites par le fils Jean au moment de l'avancée des troupes allemandes en mai 1940. Mais on dispose néanmoins, de 1894 à 1921, d'un ensemble de lettres qui dévoilent la personnalité profonde de l'auteur, au-delà du personnage public qu'elle représentait. On constate ainsi ses préoccupations constantes à l'égard non seulement des membres de sa famille, mais aussi de ses amis et relations, en particulier pour les questions de santé. Ceci malgré une activité professionnelle d'une intensité tout à fait extraordinaire: inspections dans toute la France; conférences; rapports avec les pouvoirs publics, 
régionaux ou nationaux; initiatives diverses contre la misère des enfants et pour la promotion des femmes. On est aussi frappé par son esprit caustique, car profondément républicaine et ne reniant nullement ses convictions, elle n'hésite pas à fustiger de quelques qualificatifs cinglants tel ou tel représentant du pouvoir («fumiste» pour Gabriel Compayré ; "gouape » pour Aristide Briand; "mâchoire de bestiau » pour Gaston Doumergue...). En plus des lettres écrites de la main de Pauline Kergomard ellemême, on trouve aussi une correspondance entre son père, Jean Reclus, et son beaufrère, Benjamin Laurand, témoignant de leurs inquiétudes au sujet de son mariage avec Jules Duplessis-Kergomard, homme de lettres désargenté et n'ayant guère le goût du travail. Cet ensemble de correspondances est accompagné de textes complémentaires fort utiles : une longue introduction de l'historien Jean-Noël Luc, des commentaires et témoignages des enfants et petits-enfants, un index (qui aurait mérité d'être plus précis et complété), le discours de Paul Lapie aux obsèques de l'inspectrice en 1925, deux rapports d'inspection générale adressés au ministre, l'un de 1880, l'autre de 1881.

\section{NOTES}

1. Éric Plaisance : Pauline Kergomard et l'école maternelle, Paris, PUF, 1996, 127 p. 